\title{
A new model of ragweed pollen release based on the analysis of meteorological conditions
}

\author{
L. Menut ${ }^{1}$, R. Vautard $^{2}$, A. Colette $^{3}$, D. Khvorostyanov ${ }^{1}$, A. Potier ${ }^{1}$, \\ L. Hamaoui-Laguel ${ }^{2}$, N. Viovy ${ }^{2}$, and M. Thibaudon ${ }^{4}$ \\ ${ }^{1}$ Laboratoire de Météorologie Dynamique, Palaiseau, France \\ ${ }^{2}$ Laboratoire des Sciences du Climat et de l'Environnement, Gif sur Yvette, France \\ ${ }^{3}$ INERIS, Verneuil en Halatte, France \\ ${ }^{4}$ RNSA, Brussieu, France
}

Received: 5 March 2014 - Accepted: 15 April 2014 - Published: 30 April 2014

Correspondence to: L. Menut (menut@Imd.polytechnique.fr)

Published by Copernicus Publications on behalf of the European Geosciences Union.

10891

\begin{abstract}
In order to propose a new deterministic ragweed pollen emission scheme, the meteorological conditions conducive to common ragweed pollen emission are studied over Europe between 2005 and 2011. Correlations are calculated between daily modelled 5 meteorological variables (wind speed, temperature, humidity, precipitations rates, surface fluxes) and surface concentrations at nine stations in Hungary, Croatia and France. We found that the $2 \mathrm{~m}$ temperature is the most correlated parameter, followed by convective velocity and incoming shortwave radiation. On the other hand, the precipitation rate and the $2 \mathrm{~m}$ specific humidity act as limiting factors. A new emission scheme is de-

10 signed. Compared to two existing schemes, we show that it is able to better estimate the daily release of ragweed pollen in $73 \%$ of modelled cases.
\end{abstract}

\section{Introduction}

The Ambrosia artemisifolia or common ragweed is an invasive weed, recognized for its atopic properties. For both event analysis and operational forecast, numerous ef-

15 fort were devoted to model its emission and transport. A recent overview of ragweed studies, Smith et al. (2013), showed that ragweed modelling is conducted using local statistical models (using observed meteorological data for example), trajectories models, multi-parameters regression analysis as well as regional mesoscale models. Ragweed emissions are often derived with modified birch pollen emission schemes, 20 a tree historically more documented than ragweed.

Assessing and predicting ragweed pollen emissions is challenging because they are sensitive to different botanical and meteorological factors. First, even though major efforts are currently made (see eg. Bullock et al., 2012; Chapman et al., 2014), the location of ragweed plants is difficult to establish, as recently presented in Thibaudon et al. (2014) for France. Second, for an area with clearly identified ragweed, seasonal weather conditions determine the phenology of the plant and its pollen production. 
Depending on these seasonal conditions, the yearly amount of pollen may be very different from one year to another. Finally, if the plants are present and climate conditions are favourable to the plant growth and flowering, hourly meteorological variability strongly influences the pollen release.

5 A wealth of observational data were analyzed to better understand the physical mechanisms underlying pollen emissions. A key reference is the study of Holmes and Bassett (1963) with the measurements of hourly ragweed concentrations during the summer of 1961 in Ottawa. For the first time, meteorological variables (relative humidity and air temperature) were measured together with ragweed pollen concentrations.

10 It was shown that concentrations exhibited a diurnal peak during the morning when relative humidity suddenly decreased and temperature increased, except for the days when it rained. No significant relationship with wind speed was found. Laaidi et al. (2003) analyzed the ragweed pollen concentration data in Lyon (France) during the long-term period of 1987 to 1999 . Using a statistical approach to relate meteorology

15 and concentrations using a multi-parameters regression, they were able to predict the pollen season start with an error of 3 days at the maximum, and the duration of the pollen season with an error of 7 days at the maximum. Crimi et al. (2004) conducted a statistical study over the north-west of Italy during the period from 1991 to 1995: they found that Parietaria pollen concentrations were significant when the daily temperature 20 was not exceeding $21^{\circ} \mathrm{C}$ and with a diurnal range of about $5^{\circ} \mathrm{C}$. The temperature range seems to be an important control factor, indicating the dehydratation of pollens during the day, losing mass and thus more likely to be emitted under specific wind conditions. Makra et al. (2004) also analyzed observational data and studied a possible relationship between ragweed pollen and meteorology for the period of 1997 to 2001 and in

25 the city of Szeged (Hungary). They used 11 meteorological variables and proposed a complex relation to fit their data. A similar approach is presented in Kasprzyk (2008) over Rzeszow (Poland), quantifying the impact of temperature and wind speed on ragweed emissions. Finally, these studies correspond to the "local" approach in Fig. 1: the strength of such studies is that they are close to the processes and are able to

10893

evaluate emissions taking into account the spatial representativeness of the measured concentrations. On the other hand, these studies are mainly useful for analysis of past or present conditions, (ii) the pollen transport is not taken into account. Our aim here is to identify main emission drivers at the scale of the European continent.

5 Regional modelling (Fig. 1) was initiated to better understand, quantify and predict the individual processes driving concentrations variability (emission fluxes, long range transport, deposition). It has motivated the development of pollen emission parameterizations. Over the recent years, a few schemes were proposed to estimate the pollen emissions fluxes. Helbig et al. (2004) proposed a scheme for pollen emission 10 and re-suspension with the KAMM/DRAIS model. In their model pollen emissions are computed using a "characteristic" concentration (the sum of grains measured over one season), the Leaf Area Index of the corresponding model grid cell and the friction velocity $u_{*}$ acting as a limiting factor. Pollen emissions are considered as a threshold process, similar to the saltation of mineral dust over arid areas. That is why resistances

15 based on relative humidity and wind speed are included. Zink et al. (2012) used the COSMO-ART model to analyze a pollen episode observed over northern Germany in September 2006. They compared the local contribution and the import from Hungary (one of the European countries most exposed to ragweed spread) and found that at least $20 \%$ of the pollen counts could be attributed to transboundary inflow. Sofiev

20 et al. (2006) presented the first birch pollen forecast model, integrated in the SILAM model and applied over the whole western Europe. The emissions were statistically prescribed. A few years later, Sofiev et al. (2013) presented a deterministic emission module, with the flowering season driven by the heat sum and including a probabilistic term. The module was limited to birch pollen emissions. Efstathiou et al. (2011) re-

25 cently implemented a modified Helbig et al. (2004) scheme in CMAQ and modelled the pollen period of 2002 over Newark (United States, NJ). More recently, Zink et al. (2013) presented a tunable scheme for different kind of pollen (birch, ragweed). This scheme corresponds to the best fit between modelled emissions and recorded concentrations over several sites in Europe. However, correlations between observations and simu- 
lations were found to be insignificant. Finally, Prank et al. (2013) proposed a scheme for ragweed emissions, dedicated to pollen forecasts. But in this formulation, the daily release is fixed and not depending on meteorology.

In this paper, several meteorological variables are compared to local observations to 5 identify possible correlations. Since collocated pollen-weather observations, including a consistent set of weather variables, are generally not available, and to use the same weather model as the one driving pollen count prediction, we use here outputs from a mesoscale meteorological model. This choice also follows the "mesoscale" way as described in Fig. 1. For representativeness and accuracy reasons, the low-resolution

- meteorological model can deviate from the actual meteorological context of the observation site. However it remains the best available method to assess the capability of such regional models to calculate pollen concentrations over large areas, for past, present, and future studies (such as climate scenario studies). The observations from 2005 to 2011 and the model used are described in Sect. 2. Correlations between mea-

15 sured concentrations and several modelled meteorological variables are presented in Sect. 3. The main rationale for the pollen emissions models is presented in Sect. 4. Among all processes for ragweed emissions, we focus on the daily release. Therefore, we implemented the emission schemes of Efstathiou et al. (2011) and Sofiev et al. (2013) to benchmark the capability of various existing approaches to estimate the daily

20 variability of emitted pollens. In addition, a new scheme based on temperature, specific humidity and precipitation rate is proposed. The comparison between these three schemes is performed by investigating the correlation between the release term and ragweed pollen concentrations measurements in Sect. 5. Finally, conclusions and perspectives are proposed in Sect. 6.

\section{Observations and model}

This section presents pollen observations datasets used in this study, as well as the meteorological variables. Pollen counts are recorded at in-situ stations which are rep-

10895

resentative of a few hundred meters around the instrument. In order to compare these measured concentrations with meteorological variables, we could have used locally observed meteorological data or local meteorological model outputs (such as Large Eddy Simulation models), or meteorological fields after data assimilation. Here we correlate 5 measured pollen concentrations with meteorological variables obtained from state-ofthe-art simulations used for regional modelling studies.

\subsection{Pollen observations data}

Nine observation sites are used in this study and their locations are given in Table 1. The selection of the sites was based on the availability of 33 sites across Europe at 10 the time of the study, and on the basis of the mean pollen load. Most loaded sites were selected in order to have a set of sites where the fraction of count due to local emissions is maximized vs. regional transport. These sites are located in Croatia (HR), Hungary (HU) and France (FR). Sites were also selected for their satisfactory data completeness (from $71 \%$ to $100 \%$ ). For each year and each station, the percentage

15 of available data is given in Table 1. Note that for the stations VELIKA, SAMOBOR, IVANIC, and SLAVONSKI, there are no observations for the years 2005 to 2007.

\subsection{Meteorological model configuration}

As argued in the Introduction, this study compares measured ragweed pollen concentrations to simulated meteorological variables. The meteorological variables to be 20 correlated with pollen counts are obtained from a simulation using the WRF regional model in its version 3.3.1. The model is used in its non-hydrostatic configuration, with a horizontal resolution of $0.44^{\circ} \times 0.44^{\circ}$ and 32 vertical levels from the surface to $50 \mathrm{hPa}$, a similar configuration as that used in the EURO-CORDEX project Jacob et al. (2014); Vautard et al. (2013). Evaluation of a similar WRF configuration was made in (Menut et al., 2013b). The simulation uses ERA-Interim boundary conditions, as for the EUROCORDEX simulations (Vautard et al., 2013; Kotlarski et al., 2014) but uses here of 
a spectral nudging technique for the upper-air winds. This choice was made in order to allow the model to follow the large-scale circulation while leaving unconstrained the model physics.

For the microphysics, the WRF Single Moment-5 class scheme is used allowing for 5 mixed phase processes and super cooled water (Hong et al., 2004). The radiation scheme is RRTMG scheme with the MCICA method of random cloud overlap (Mlawer et al., 1997). The surface layer is based on the Monin-Obukhov scheme with CarslonBoland viscous sub-layer. The surface physics is calculated using the Noah Land Surface Model scheme with four soil temperature and moisture layers (Chen and Dudhia,

10 2001). The planetary boundary layer physics is processed using the Yonsei University scheme (Hong et al., 2006) and the cumulus parameterization uses the ensemble scheme of Grell and Devenyi (2002). This model configuration is the same as that of Vautard et al. (2013).

The meteorological variables used in this study are extracted from the grid cell cor-

15 responding to the station location at a temporal frequency of tqhree hours. These variables are listed in Table 2.

\section{Statistics between ragweed pollen concentrations and meteorological vari- ables at daily time scale}

\subsection{The statistical calculations}

20 In order to calculate the correlation between the meteorological datasets, the parameterized emissions and the observed surface concentrations, the Pearson's product moment correlation coefficient, $r$, is calculated as:

$$
r=\frac{\sum_{i=1}^{n}\left(x_{i}-\bar{x}\right)\left(y_{i}-\bar{y}\right)}{\sqrt{\sum_{i=1}^{n}\left(x_{i}-\bar{x}\right)^{2}} \sqrt{\sum_{i=1}^{n}\left(y_{i}-\bar{y}\right)^{2}}}
$$

10897

This Pearson correlation coefficient is the ratio of the covariance between two data sets $x$ and $y$ and the product of their two standard deviations. A value of 1 is a complete positive correlation. Similarly, a value of -1 represents a complete negative correlation. An important additional information is the significance of this correlation. It is estimated 5 following the Student'law probability $p_{\mathrm{sl}}$. The closer $p_{\mathrm{sl}}$ is to zero, the more significant the correlation.

\subsection{Results}

Following the previous studies, some meteorological variables are of particular importance for pollen emissions. For birch pollen, Helbig et al. (2004) showed that the most important parameter to take into account is the friction velocity. The surface temperature and relative humidity, as well as the wind speed, act as resistances to this emission flux. Sofiev et al. (2013) used the temperature heat-sum function to estimate the starting season, and the flux is moderated by meteorological factors such as the wind speed, the relative humidity, and the precipitation rate.

15 In this study, the correlation between ragweed pollen concentrations and meteorology is estimated variable by variable. Since the ragweed emission process is different from that of birch, we increase the number of potentially correlated parameters. In order to take into account the specific plant phenology, its height above the ground, its sensitivity to temperature and humidity, the examined meteorological variables are listed in 20 Table 2. For each parameter, the temporal averaging is also reported.

Note that the ragweed plant being close to the ground, the $10 \mathrm{~m}$ wind speed is not taken account, the near-surface dynamical processes being better represented by the friction velocity, $u_{*}$.

The results of correlations between ragweed pollen concentrations and meteorolog25 ical variables are presented in Table 3 for some sites and for the year 2010 as an example. The correlation $r$ is given, as well as the corresponding significance $p_{\mathrm{sl}}$ in parentheses. The largest two correlations are boldfaced. The results are dispersed and there is no meteorological parameter with a systematically high correlation value. 
However, the highest correlations are for the $2 \mathrm{~m}$ temperature, with values ranging between 0.3 and 0.66 . While experimental studies have shown that ragweed pollen emissions are more intense during the morning and thus depend on the morning temperature gradient, this does not clearly appear in our results. Recent studies have

5 also shown that $\mathrm{SW}_{\mathrm{d}}$ is an important factor for ragweed pollen emissions: it clearly appears in our correlations, with values ranging between 0.12 and 0.38 for the daily mean $\left(d_{\text {mean }}\right)$ or the daily maximum $\left(d_{\text {max }}\right)$. Furthermore fair correlation values are found for $w_{*}$. This shows that the emissions are sensitive to the near-surface turbulent heat fluxes. For the four sites, the correlations range from 0.04 to 0.43 , with mostly significant values.

Surprisingly, the correlations between concentrations and $\operatorname{Pr}$ and $q_{2 \mathrm{~m}}$ are not systematically negative. For example, for ROUSSILLON and HUDEBR, the correlation is positive for $q_{2 \mathrm{~m}}$, whereas humidity is known to inhibit pollen emissions. Finally, the highest correlations are found for thermal and radiative parameters, $T_{2 m}$ and $S W_{d}$, rather

15 than dynamical parameters. The choice of a "time window" (e.g. daily mean or daily $\max$ ) is not significant, except the morning for which the correlations are very low and not significant.

\section{Modeling ragweed pollen emission}

The previous section focused on the correlations between ragweed pollen concentra20 tions and meteorological variables. We found that the highest correlations are found for $2 \mathrm{~m}$ temperature $T_{2 \mathrm{~m}}$, vertical turbulent velocity $w_{*}$ and downward shortwave radiation flux, $\mathrm{SW}_{\mathrm{d}}$. But these correlations were estimated variable by variable and therefore they do not account for the possible interactions between these meteorological variables.

We propose in this section a new formulation for ragweed pollen emissions. Rag25 weed pollen emissions are not measured, therefore the emission model results are calibrated directly with ragweed pollen concentrations. Thus, the first hypothesis is to consider than the ragweed surface concentration measurements may be considered

10899

here as a proxy for the emissions to estimate. This is possible only if the measurement station is very close to the sources: that is why the stations retained in this study correspond to this "proximity" criterion.

The emission flux $E(x, y, t)$ is expressed in grains $\mathrm{m}^{-2} \mathrm{~s}^{-1}$ as:

$5 \quad E(x, y, t)=D(x, y) \times P(x, y, t) \times \phi(x, y, t) \times R(x, y, t)$

where:

- $D(x, y)$ is the ragweed density distribution in number of individual plants per square meter.

$10-P(x, y, t)$ is the annual production in grains per individual plant.

- $\phi(x, y, t)$ is the phenology factor in $\mathrm{s}^{-1}$, considering its yearly integrated value is unity. This factor represents the knowledge of the start and end date of the pollen season as well as the shape of these potential emissions.

- $R(x, y, t)$ is the daily or sub-daily weather-dependent release of pollen grains in the atmosphere which depends on the hourly (or daily) meteorological variables. $R(x, y, t)$ is unitless.

These different terms correspond to two different temporal scales:

- $D(x, y), P(x, y, t)$ and $\phi(x, y, t)$ represent "annual" information.

- $R(x, y, t)$ represents the "short-term" information for which we want to evaluate correlation with the meteorological variables.

In this work, we focus on the calculation of $R(x, y, t)$ to study the daily correlations between meteorology and pollen emissions (via the pollen concentrations). Thus, in order to compare emissions and concentrations, we have to make specific hypotheses for the "annual" terms, $D(x, y), P(x, y, t)$ and $\phi(x, y, t)$. 


\subsection{Annual pollen production}

The term $D(x, y) \times P(x, y, t)$ corresponds to the annual production of grains for one plant multiplied by the number of plants per square meter. Here we consider this term as equal to the sum of daily counts measured during one year at a given measurement

5 station. Hence we assume a linear relationship between emissions and concentrations, which could be satisfied under the following conditions: (i) the measurements are close to the emission sources; (ii) the emitted grains are homogeneously vertically mixed; (iii) all the grains produced by the plants during the pollen season are eventually emitted during the season.

10 This annual sum is displayed in Fig. 2. Previous studies mainly used constant values for each location and for several years. However, our results show a large interannual variability of the number of grains produced. The stations of HRZAGR, ROUSSILLON and HUGYOE exhibit relatively constant and, compared to the other stations, low values for all years (between 3000 to 8000 grains $\mathrm{m}^{-3}$ ). For these regions, the use of 15 a constant value may be an acceptable first guess. But, the stations of HUDEBR or SLAVONSKI show a very important year to year variability, from 2000 to 15000 grains $\mathrm{m}^{-3}$. This variability can be related to interannual changes in (1) the annual production of grains by the plants $P(x, y, t)$; (2) the fraction of grains released during the year; (3) the number of plants $D(x, y)$ available each year. We conclude that the use of a con-

20 stant value could impact the calculated emissions in a unrealistic way. Therefore, we used the measurements for each year and each station, which was possible since we focus on specific locations only. For use in a transport model, this hypothesis would have to be substituted by a deterministic calculations using another model to provide this information, e.g., a simulation with a hydrology/vegetation model.

10901

\subsection{Phenology factor}

The phenology factor $\phi(x, y, t)$ is calculated as:

$\phi(x, y, t)=\exp \left[-\alpha\left(\frac{j-\beta\left(j_{\mathrm{s}}+j_{\mathrm{e}}\right)}{j_{\mathrm{e}}-j_{\mathrm{s}}}\right)^{2}\right]$

${ }_{5}$ where $j_{\mathrm{s}}$ and $j_{\mathrm{e}}$ are the julian days of the start and end of the "pollen season", $\alpha$ and $\beta$ are arbitrary constant values.

Since we focus on the release factor, the values of $j_{\mathrm{s}}$ and $j_{\mathrm{e}}$ are fitted from the observed ragweed concentrations data. Following Laaidi et al. (2003), among others, the pollen season start can be diagnosed as the day when the pollen concentration cumulated from the beginning of the flowering season reaches $5 \%$ of the total pollen count over the same year. Following the same idea, the end of the pollen season occurs when the cumulated pollen concentration reaches $95 \%$ of the total yearly sum. The results are presented in Table 4 for each station and each year. We can notice a some variability from year to year and over all stations: the pollen season starting date can

15 vary up to 8 days, while the pollen season duration ranges from 21 to 49 days. Due to this variability, we will use actual observed $j_{\mathrm{s}}$ and $j_{\mathrm{e}}$ at each station in the following of this study.

In Eq. (3), $\alpha$ and $\beta$ define the width and the peak time of the phenology function, respectively. These values cannot be estimated by a vegetation/hydrology model de20 pending on an intra-seasonal variability. For this study, we thus have to prescribe these values based on a common sense. $\alpha$ and $\beta$ are set constant for all years and all stations. In the absence of usable constraint, we will use the most neutral values. The value of $\beta=0.5$ is selected to have the maximum of pollen concentration in the middle of the season. For the shape of the pollen season, $\alpha=20$ appears to be a right value 25 to constrain the pollen season within $j_{\mathrm{S}}$ and $j_{\mathrm{e}}$. 


\subsection{The instantaneous release factor}

The instantaneous release factor $R(x, y, t)$ is designed to capture the daily variability of pollen emissions. Several formulations are currently proposed for pollen emission. This study presents a new scheme that is compared to the existing parameterizations of

5 Sofiev et al. (2013) and Efstathiou et al. (2011). It is important to notice that the scheme of Sofiev et al. (2013) was not originally developed for ragweed pollen emissions but for birch pollen emissions. But since the existing parameterizations for ragweed pollen are scarce, it was used for ragweed by Prank et al. (2012) with SILAM as explained by Smith et al. (2013). The scheme proposed by Efstathiou et al. (2011) was developed to estimate birch and ragweed pollen emissions with the same formulation but after some adjustments.

\subsubsection{Previous studies}

The study of Sofiev et al. (2013) (hereafter called S2013) presents a very complete scheme for the pollen release here noted $R_{\mathrm{s}}$ :

$15 \quad R_{\mathrm{s}}=\left(f_{\text {windmax }}-\exp \left[\frac{-\left(U_{10 \mathrm{~m}}+w_{*}\right)}{U_{\text {satur }}}\right]\right) \times f_{\text {cond }}\left(\mathrm{rh} \cdot \mathrm{rh}_{\mathrm{fac}}, \mathrm{rh}_{\text {low }}, \mathrm{rh}_{\text {high }}\right)$ $\times f_{\text {cond }}\left(\operatorname{Pr} \cdot \operatorname{Pr}_{\text {fac }}, \operatorname{Pr}_{\text {low }}, \operatorname{Pr}_{\text {high }}\right)$

with $f_{\text {windmax }}\left(\mathrm{m} \mathrm{s}^{-1}\right)$ a maximum value chosen as $f_{\text {windmax }}=1.5, U_{10 \mathrm{~m}}$ the $10 \mathrm{~m}$ wind speed, $w_{*}$ the turbulent vertical velocity scale, rh the relative humidity (\%), Pr the precipitation rate $\left(\mathrm{mm} \mathrm{h}^{-1}\right)$. The fixed parameters are $\mathrm{rh}_{\mathrm{fac}}=100 \%, U_{\text {satur }}=5 \mathrm{~ms}^{-1}$ and the "precipitation rate factor", $\operatorname{Pr}_{\mathrm{fac}}=1$.

10903

$f_{\text {cond }}\left(x, x_{\min }, x_{\max }\right)$ is a conditional function expressed as:

$f_{\text {cond }}= \begin{cases}0 & \text {, if } x>x_{\max }, \\ 1 & , \text { if } x<x_{\min }, \\ \frac{x_{\max }-x}{x_{\max }-x_{\min }} & , \text { if } x_{\min }<x<x_{\max },\end{cases}$

This function is applied to moderate the influence of the precipitation rate and the 5 relative humidity on pollen release. The boundary values are chosen as: $\mathrm{rh}_{\text {low }}=50 \%$, $\mathrm{rh}_{\text {high }}=80 \%, \mathrm{Pr}_{\text {low }}=0 \mathrm{mmh}^{-1}, \mathrm{Pr}_{\text {high }}=0.5 \mathrm{mmh}^{-1}$.

The study of Efstathiou et al. (2011) (hereafter called E2011) used the same kind of scheme for birch and ragweed pollen release. The difference with Sofiev et al. (2013) is an additional term using the friction velocity $u_{*}$ and canopy height, $H_{\mathrm{c}}$. We consider 10 for this study $H_{\mathrm{c}}=1 \mathrm{~m}$ for ragweed plants. All other parameters are similar. This leads to the expression of the release rate $R_{e}$ as:

$$
\begin{aligned}
R_{e}= & \frac{u_{*}}{H_{\mathrm{c}}} \times\left(f_{\text {windmax }}-\exp \left[\frac{-\left(U_{10 \mathrm{~m}}+w_{*}\right)}{U_{\text {satur }}}\right]\right) \times f_{\text {cond }}\left(\mathrm{rh} \cdot \mathrm{rh}_{\mathrm{fac}}, \mathrm{rh}_{\text {low }}, \mathrm{rh}_{\text {high }}\right) \\
& \times f_{\text {cond }}\left(\operatorname{Pr} \cdot \operatorname{Pr}_{\text {fac }}, \operatorname{Pr}_{\text {low }}, \operatorname{Pr}_{\text {high }}\right)
\end{aligned}
$$

\section{$15 \quad$ 4.3.2 This study}

Based on the correlation results of Sect. 3, it appears that the main driving factors for ragweed emissions are neither dynamical variables (wind speed, $u_{*}$, boundary layer height) nor precipitations. The most highly correlated variables are those related to thermodynamical processes, namely the $2 \mathrm{~m}$ temperature, $T_{2 \mathrm{~m}}$, vertical velocity scale $20 \quad W_{*}$ and short-wave radiation $S_{\mathrm{d}}$. The pollen emissions may be moderated by precipitation rates $\operatorname{Pr}$ and $2 \mathrm{~m}$ specific humidity $q_{2 \mathrm{~m}}$.

The differences between birch and ragweed emissions could be explained by the plant typology itself: birch is a tree, with the pollen source up to $10 \mathrm{~m}$ above the ground. 
At this level, the wind may be considered as a dominant process for emission of grains. Ragweed rarely exceeds 1 to $2 \mathrm{~m}$ above the ground, where the wind speed is moderate. In this case, the dominant factor could be the temperature, considering the grains are emitted under highest temperature when they are sufficiently dry (Holmes and Bassett,

5 1963). The precipitation rate is a limiting factor but not the most important one: even if it rains during the night, the grains can dry out and can be pulled off the plant in the morning.

The instantaneous release factor $R_{\mathrm{ts}}$ (with TS for "this study") is thus estimated as:

$$
R_{\mathrm{ts}}=\frac{\frac{T_{2 \mathrm{~m}}}{T_{2 \mathrm{~m}, 0}} \times \frac{w_{*}}{W_{*, 0}} \times \frac{\mathrm{SW}_{\mathrm{d}}}{\mathrm{SW}} \mathrm{SW}_{d, 0}}{r_{q_{2 \mathrm{~m}}}+r_{\mathrm{Pr}}}
$$

where the values of $T_{2 m}, w_{*}$ and $\mathrm{SW}_{\mathrm{d}}$ correspond to the mean daily value. These values are normalized in order to keep the release term nondimensional. The normalization factors are $T_{2 \mathrm{~m}, 0}=10^{\circ} \mathrm{C}, w_{*, 0}=1 \mathrm{~ms}^{-1}$ and $S W_{d, 0}=200 \mathrm{Wm}^{-2}$.

In order to moderate these fluxes when meteorological conditions are not favourable,

15 resistances terms are added. These resistances are mainly due to the $2 \mathrm{~m}$ specific humidity $q_{2 \mathrm{~m}}$ and the precipitation rate Pr. Each resistance is expressed as a sigmoid function ranging between 0 and 1, depending on minimal and maximal value of the $x$ parameter. The resistance has to reflect the fact that these parameters inhibit ragweed pollen emissions.

$20 \quad r_{x}=1+\exp \left[\frac{-b_{f}\left(i_{\max }-i_{\min }\right)}{2}\left(\frac{x}{x_{\max }-x_{\min }}-1\right)\right]$

with $b_{f}$ being a constant chosen here as $b_{f}=10$, that determines the curve of the sigmoid function. $i_{\min }$ and $i_{\max }$ represent the range of the sigmoid and are here

10905

chosen as $i_{\min }=0$ and $i_{\max }=1$ in order to use a normalized function for each resistance. The critical issue here is to choose the minimum and maximum value for each $x$ meteorological parameter. These boundaries have to reflect the best possible range of variations of meteorological variables, for all locations over Europe and 5 for the whole year. The maximum values must be moderate enough in order to provide a realistic resistance: a too low maximum value would give a resistance of 1 too often, while a too high maximum value would give too low resistances. Based on all meteorological values used in this study, the boundaries for the $2 \mathrm{~m}$ specific humidity are $q_{2 \mathrm{~m}}(\min )=0$ and $q_{2 \mathrm{~m}}(\max )=5 \times 10^{-3} \mathrm{gg}^{-1}$ and for the precipitation rate are $10 \operatorname{Pr}(\min )=0$ and $\operatorname{Pr}(\max )=1.5 \mathrm{mmh}^{-1}$.

An example of resistances is given for years 2007 and 2011 for the station ROUSSILLON, in Fig. 3. The resistance values vary from 0 to 1 . For $r=0$, there is no limitation to the process. For higher values of $r$, the emission is attenuated if the two resistances act at the same time. For the two years, the resistance due to the specific humidity 15 exhibits large variations between 0.1 and 0.8 . This corresponds to periods of several days of successive dry and wet synoptic meteorological conditions. The resistance for the precipitation rate is also between 0 and 1 , but mainly with zero values and with sporadic peaks corresponding to precipitation events. Sensitivity tests were done to evaluate the impact of the precipitation resistance, and more precisely, the choice

20 of the $\operatorname{Pr}(\max )$ value. This parameter is very sensitive and, logically, must be low to inhibit emissions during rainy periods. Finally, we retained a relatively high value of $\operatorname{Pr}(\max )=1.5 \mathrm{mmh}^{-1}$ : (i) to adjust this resistance because it was shown that precipitation is not a terminal inhibitor for ragweed pollen, in contrast to birch pollen, (ii) because the simulated precipitation rate is a highly uncertain meteorological diagnostic. Giving

25 a too strong weight to the precipitation rate in the emission calculations would lead to less realistic emission fluxes for the wrong reasons. 


\section{Comparisons between observations and model}

The observed ragweed pollen concentrations are compared to emission fluxes. First, correlations between concentrations and emissions are calculated for all stations and years for which observational data are available. Second, time series are presented

5 for several stations for 2010. Finally, a focus is put on several stations, including an analysis of the meteorological conditions, to better understand when emissions are correctly estimated or not.

\subsection{Correlations}

Correlations between modelled emissions and observed ragweed concentrations are 10 presented in Tables 5 and 6 . One correlation value is calculated for each year (i.e each pollen season) and each site. For each correlation value, the significance is also calculated and presented in parenthesis.

The correlations are very variable but for a major part, the results are significant (with $p_{\mathrm{SI}}=0$ ). It is the case for the stations of BJELOVAR, HRZAGR, ROUSSILLON,

15 SAMOBOR, SLAVONSKI and VELIKA for the three parameterizations. For HUDEBR, only our parameterization provides significant results.

The new scheme (based on surface layer thermal properties) gives comparable or better results than the parameterizations E2011 and S2013 based on dynamical processes. For the 46 studied cases, the new scheme provides better results for 36 case 20 studies, i.e. in $73 \%$ of cases. For comparison, E2011 and S2013 provide the best results in $9 \%$ and $18 \%$ of all cases, respectively.

\subsection{Time series of ragweed emissions and concentrations}

In order to better understand the daily variability of ragweed pollen emissions, Fig. 4 compares the observed ragweed pollen concentrations to the emission fluxes calcu-

lated using the three schemes. Results are presented for the stations ROUSSILLON,

10907

HUDEBR, HRZAGR and VELIKA, and for the years 2009, 2010 and 2011. Note that these pollen observations and meteorological variables time series are normalized by their maximum value (over the whole season), in order to plot all the data on the same figure.

5 As per Eq. (2), the modelled emissions can depend on the yearly mass of pollen, the phenology factor and the daily release. In this study, the annual mass and the phenology factor remain the same for the three emission calculations: only the daily release term is different and will be discussed here.

For the ROUSSILLON station, Fig. 4 (top), the correlations are good for the three schemes: the new scheme has a better correlation but the values are always greater than 0.45 for all schemes. The case of 2009 will be precisely discussed in the next section. In 2010, the three schemes fail to estimate the sudden decrease of concentrations for the julian days between 230 and 250. In 2011, the three schemes give good results and are similar to each other: they are all able to diagnose the first half of the season

15 with high emissions (for days 235 to 250 ) and the decay of pollen production for days 250 to 270 over the end of the season.

For the HUDEBR station, Fig. 4 (middle), correlations are lower than for ROUSSILLON, ranging between 0.15 (for E2011 in 2011) to 0.67 (for TS in 2009). In contrast to ROUSSILLLON, the concentration seasonal cycle does not exhibit a bell shape: ob-

20 served values are dispersed from one day to another. During the year 2010, it is noteworthy that pollen concentrations exhibit a sudden drop in the middle of the season. In this case, only the TS scheme is able to model these low values, therefore a better correlation. But for the rest of the season, none of the schemes is able to reproduce the observed variability.

25 For the HRZAGR station, Fig. 4 (middle), and for 2009, the three schemes totally miss the season by simulating the highest values in the early days, while the maxima are observed at the end of the season. In 2010, the TS scheme gives better scores mainly for not simulating the peak in the middle of the season, around the day 245 . In 2011, the best correlation is obtained with the S2013 scheme, mainly because it is 
able to reproduce higher values at the beginning of the season (around day 232) and moderate values in the middle of the season.

For the VELIKA station, Fig. 4 (bottom), and in 2009, results are better for the TS scheme because E2011 and S2013 produce spurious peaks during days 234 and 242.

5 The 2010 case is a good example of low score with the TS scheme and is discussed in more details in the next section. For 2011, the three schemes give low correlations (from 0.34 to 0.44 ): none of them is able to simulate the large peak early in the season and the low values at the end of the season.

\subsection{Focus on two specific events}

10 Figure 5 focusses on two specific sites and periods in order to better understand the relationship between meteorological variables and observed concentrations. These time series present daily values. All time series are normalized by the maxima over the whole period, in order to have only variations between 0 and 1.

For the ROUSSILLON station in 2009, correlations are $0.54,0.62$ and 0.74 for the

15 schemes E2011, S2013 and TS, respectively. For this year and this station, all schemes are thus able to simulate quite well the ragweed pollen emissions. The concentration peaks on day 230 , which corresponds to the maximum temperature for this period. In addition, the humidity is moderate, and no precipitation is simulated. During the middle of the pollen season, the concentration becomes very low (between days 236 and 238) 20 which coincides with the precipitation peak and the decrease of $S W_{d}$ and $w_{*}$.

For the VELIKA site in 2010, the observed concentrations show an atypical seasonal cycle with two major peaks and very low concentrations in the middle of the season. The correlation are $0.45,0.5$ and 0.30 for the schemes E2011, S2013 and TS, respectively. In this case, the new scheme TS gives the worst score. This is mainly due to

25 these two peaks: for the first concentration peak on day 236, the temperature reaches its maximum, but $w_{*}$ and $S W_{d}$ are close to their minima, leading to a low release rate, contrary to the observations. For the second peak, the modelled temperature is very low, leading to low modelled emissions, while observations exhibit a maximum.

10909

\section{Conclusions}

This study was dedicated to the identification of daily meteorological conditions favourable to ragweed pollen emissions. To estimate this dependency, meteorological fields, modelled with WRF, were compared to measured concentrations over several 5 sites in Europe for the period from 2005 to 2011.

The first step was to compare daily meteorological variables to surface ragweed pollen concentrations. Our statistical analysis clearly shows that the highest concentrations recorded during a season are more sensitive to thermal parameters $(2 \mathrm{~m}$ temperature) than dynamical variables (wind speed, friction velocity). Over the course of

10 a given day, the measured ragweed pollen emissions were found to occur mainly in the morning. Investigation was performed to estimate if modelled emissions were rather sensitive to the daily mean value, the daily max or the mean morning value: no significant result was found. This means that, while hourly measurements showed the highest ragweed pollen emissions to occur in the morning, the meteorological model is 15 not able to simulate well enough this hourly variability.

In order to better understand the ragweed pollen emissions sensitivity to meteorology, a new emission scheme is proposed. Existing schemes Efstathiou et al. (2011) and Sofiev et al. (2013) were developed for birch and ragweed pollen emissions; both of them are based on the thermal and dynamical processes in the atmospheric surface

20 layer. Our new scheme takes stock of the outcome of the correlation analysis in the first part of the study and therefore relies on thermal, turbulent, and radiative processes using the $2 \mathrm{~m}$ temperature, $T_{2 \mathrm{~m}}$, the convective velocity scale $w_{*}$ and the downward shortwave radiative flux $S W_{d}$. The focus is on the daily pollen release process, assuming that the beginning and the end of the flowering season, and the total amount of

25 the released pollen, are known. For this study, we derived these quantities from the measurements. For nine stations in Europe and six years of daily measurements, correlations were calculated between daily release rate and surface concentration measurements. It was shown that our new scheme is able to give better correlations in $73 \%$ 
of the cases. A next step for ragweed pollen emission modelling would be to include this new scheme in a transport model as planned for the regional chemistry-transport model CHIMERE (Menut et al., 2013a), forced by pollen phenology and production prescribed with the hydrology and vegetation model ORCHIDEE (Krinner et al., 2005).

5 Acknowledgements. The research leading to these results has received funding from the European Union's Seventh Framework Programme (FP7/2007-2013) under grant agreement $n^{\circ} 282687$ - Atopica (www.atopica.eu).

\section{References}

Bullock, J. M., Chapman, D. S., Schafer, S., Roy, D. B., Girardello, M., Haynes, T., Beal, S., Wheeler, B., Dickie, I., Phang, Z., Tinch, R., Civic, K., Delbaere, B., Jones-Walters, L., Hilbert, A., Schrauwen, A., Prank, M., Sofiev, M., Niemela, S., Raisanen, P., Lees, B., Skinner, M., Finch, S., and Brough, C.: Assessing and controlling the spread and the effects of common ragweed in Europe, Tech. rep., European Commission Final Report ENV.B.2/ETU/2010/0037, Centre for Ecology \& Hydrology, Benson Lane, Wallingford, OX10 8BB, UK, 2012. 10892

Chapman, D. S., Haynes, T., Beal, S., Essl, F., and Bullock, J. M.: Phenology predicts the native and invasive range limits of common ragweed, Glob. Change Biol., 20, 192-202, 2014. 10892

Chen, F. and Dudhia, J.: Coupling an advanced land surface-hydrology model with the Penn State-NCAR MM5 modeling system. Part I: Model implementation and sensitivity, Mon. Weather Rev., 129, 569-585, 2001. 10897

Crimi, P., Macrina, G., Folli, C., Bertoluzzo, L., Brichetto, L., Caviglia, I., and Fiorina, A.: Correlation between meteorological conditions and Parietaria pollen concentration in Alassio, northwest Italy, Int. J. Biometeorol., 49, 13-17, doi:10.1007/s00484-004-0212-8, 2004. 10893

25 Efstathiou, C., Isukapalli, S., and Georgopoulos, P.: A mechanistic modeling system for estimating large-scale emissions and transport of pollen and co-allergens, Atmos. Environ., 45, 2260-2276, doi:10.1016/j.atmosenv.2010.12.008, 2011. 10894, 10895, 10903, 10904, 10910, 10920, 10922

10911

Grell, G. A. and Devenyi, D.: A generalized approach to parameterizing convection combining ensemble and data assimilation techniques, Geophys. Res. Lett., 29, 1693, doi:10.1029/2002GL015311, 2002. 10897

Helbig, N., Vogel, B., Vogel, H., and Fiedler, F.: Numerical modelling of pollen dispersion on the regional scale, Aerobiologia, 3, 3-19, 2004. 10894, 10898

Holmes, R. and Bassett, I.: Effect of meteorological events on ragweed pollen count, Int. J. Biometeorol., 7, 27-34, 1963. 10893, 10905

Hong, S. Y., Dudhia, J., and Chen, S.: A revised approach to ice microphysical processes for the bulk parameterization of clouds and precipitation, Mon. Weather Rev., 132, 103-120, 2004. 10897

Hong, S. Y., Noh, Y., and Dudhia, J.: A new vertical diffusion package with an explicit treatment of entrainment processes, Mon. Weather Rev., 134, 2318-2341, doi:10.1175/MWR3199.1, 2006. 10897

Jacob, D., Petersen, J., Eggert, B., Alias, A., Christensen, O. B., Bouwer, L. M., Braun, A., Colette, A., Deque, M., Georgievski, G., Georgopoulou, E., A.Gobiet, L.Menut, G.Nikulin, A.Haensler, N.Hempelmann, C.Jones, K.Keuler, Kovats, S., Kroner, N., Kotlarski, S., Kriegsmann, A., Martin, E., van Meijgaard, E., Moseley, C., Pfeifer, S., Preuschmann, S., Radermacher, C., Radtke, K., Rechid, D., Rounsevell, M., Samuelsson, P., Somot, S., Soussana, J.-F., Teichmann, C., Valentini, R., Vautard, R., Weber, B., and Yiou, P.: EURO-CORDEX:

20 New high-resolution climate change projections for European impact research, Reg. Environ. Change, 14, 563-578, 2014. 10896

Kasprzyk, I.: Non-native Ambrosia pollen in the atmosphere of Rzeszow (SE Poland); evaluation of the effect of weather conditions on daily concentrations and starting dates of the pollen season, Int. J. Biometeorol., 52, 341-351, 2008. 10893

25 Kotlarski, S., Keuler, K., Christensen, O. B., Colette, A., Déqué, M., Gobiet, A., Goergen, K., Jacob, D., Lüthi, D., van Meijgaard, E., Nikulin, G., Schär, C., Teichmann, C., Vautard, R., Warrach-Sagi, K., and Wulfmeyer, V.: Regional climate modeling on European scales: a joint standard evaluation of the EURO-CORDEX RCM ensemble, Geosci. Model Dev. Discuss., 7, 217-293, doi:10.5194/gmdd-7-217-2014, 2014. 10896

30 Krinner, G., Viovy, N., de Noblet-Ducoudre, N., Ogee, J., Polcher, J., Friedlingstein, P., Ciais, P., Sitch, S., and Prentice, I.: A dynamic global vegetation model for studies of the coupled atmosphere-biosphere system, Global Biogeochem. Cy., 19, doi:10.1029/2003GB002199, 2005. 10911 
Laaidi, M., Thibaudon, M., and Besancenot, J.-P.: Two statistical approaches to forecasting the start and duration of the pollen season of Ambrosia in the area of Lyon (France), Int. J. Biometeorol., 48, 65-73, 2003. 10893, 10902

Makra, L., Juhasz, M., Borsos, E., and Beczi, R.: Meteorological variables connected with airborne ragweed pollen in Southern Hungary, Int. J. Biometeorol., 49, 37-47, 2004. 10893

Menut, L., Bessagnet, B., Khvorostyanov, D., Beekmann, M., Blond, N., Colette, A., Coll, I., Curci, G., Foret, G., Hodzic, A., Mailler, S., Meleux, F., Monge, J.-L., Pison, I., Siour, G., Turquety, S., Valari, M., Vautard, R., and Vivanco, M. G.: CHIMERE 2013: a model for regional atmospheric composition modelling, Geosci. Model Dev., 6, 981-1028, doi:10.5194/gmd-6981-2013, 2013a. 10911

Menut, L., Tripathi, O., Colette, A., Vautard, R., Flaounas, E., and Bessagnet, B.: Evaluation of regional climate simulations for air quality modelling purposes, Clim. Dynam., 40, 25152533, doi:10.1007/s00382-012-1345-9, 2013b. 10896

Mlawer, E., Taubman, S., Brown, P., lacono, M., and Clough, S.: Radiative transfer for inhomo-

15 geneous atmospheres: RRTM a validated correlated-k model for the longwave, J. Geophys. Res., 102, 16663-16682, 1997. 10897

Prank, M., Sofiev, M., and Chapman, D.: Emission and dispersion of the ragweed pollen in Europe: first results and evaluation of the SILAM model, 2nd International Ragweed Conference, Lyon, France, 28-29 March 2012, Lyon, France, available at: http://www. internationalragweedsociety.org/IRC_Lyon/IRC_Poster/P5Prank.pdf (last access: 28 April 2014), 2012. 10903

Prank, M., Chapman, D., Bullock, J., Belmonte, J., Berger, U., Dahl, A., Jager, S., Kovtunenko, I., Magyar, D., Niemela, S., Rantio-Lehtimaki, A., Rodinkova, V., Sauliene, I., Severova, E., Sikoparija, B., and Sofiev, M.: An operational model for forecasting ragweed pollen release and dispersion in Europe, Agr. Forest Meteorol., 182, 43-53, 2013. 10895

Smith, M., Cecchi, L., Skjoth, C., Karrer, G., and Sikoparija, B.: Common ragweed: a threat to environmental health in Europe, Environ. Int., 61, 115-126, doi:10.1016/j.envint.2013.08.005, 2013. 10892, 10903

Sofiev, M., Siljamo, P., Ranta, H., and Rantio-Lehtimaki, A.: Towards numerical forecasting of long-range air transport of birch pollen: theoritical considerations and a feasability study, Int. J. Biometeorol., 50, 392-402, doi:10.1007/s00484-006-0027-x, 2006. 10894

Sofiev, M., Siljamo, P., Ranta, H., Linkosalo, T., Jeager, S., Rasmussen, A., RantioLehtimaki, A., Severova, E., and Kukkonen, J.: A numerical model of birch pollen emission

10913

and dispersion in the atmosphere. Description of the emission module., Int. J. Biometeorol., 57, 45-58, doi:10.1007/s00484-012-0532-z, 2013. 10894, 10895, 10898, 10903, 10904, 10910, 10920, 10922

Thibaudon, M., Sikoparija, B., Oliver, G., Smith, M., and Skjoth, C.: Ragweed pollen source inventory for France: the second largest centre of Ambrosia in Europe, Atmos. Environ., 83, 62-71, doi:10.1016/j.atmosenv.2013.10.057, 2014. 10892

Vautard, R., Gobiet, A., Jacob, D., Belda, M., Colette, A., Deque, M., Fernandez, J., GarciaDiez, M., Goergen, K., Guttler, I., Halenka, T., Karacostas, T., Katragkou, E., Keuler, K., Kotlarski, S., Mayer, S., van Meijgaard, E., Nikulin, G., Patarcic, M., Scinocca, J., Sobolowski, S.,

10 Suklitsch, M., Teichmann, C., Warrach-Sagi, K., Wulfmeyer, V., and Yiou, P.: The simulation of European heat waves from an ensemble of regional climate models within the EUROCORDEX project, Clim. Dynam., 41, 2555-2575, doi:10.1007/s00382-013-1714-z, 2013. 10896, 10897

Zink, K., Vogel, H., Vogel, B., Magyar, D., and Kottmeir, C.: Modeling the dispersion of Ambrosia artemisiifolia L. pollen with the model system COSMO-ART, Int. J. Biometeorol., 56, 669680, doi:10.1007/s00484-011-0468-8, 2012. 10894

Zink, K., Pauling, A., Rotach, M. W., Vogel, H., Kaufmann, P., and Clot, B.: EMPOL 1.0: a new parameterization of pollen emission in numerical weather prediction models, Geosci. Model Dev., 6, 1961-1975, doi:10.5194/gmd-6-1961-2013, 2013. 10894 
Table 1. List of all Ambrosia measurements stations used in this study. The stations of Debrecen, Gyoyer and Zagreb are operated by EAN network, the stations of Velika, Samobor, Ivanic, Slavonski and Bjelovar are operated by the HRTEAM network and the station of Roussillon by the RNSA network. For each year, the percentage of available data is given.

\begin{tabular}{|c|c|c|c|c|c|c|c|c|c|}
\hline Station & City/country & $\begin{array}{r}\text { Longitude }\left({ }^{\circ} \mathrm{W}\right) \\
\text { Latitude }\left({ }^{\circ} \mathrm{N}\right)\end{array}$ & $\begin{array}{r}2005 \\
\%\end{array}$ & $\begin{array}{r}2006 \\
\%\end{array}$ & $\begin{array}{r}2007 \\
\%\end{array}$ & $\begin{array}{r}2008 \\
\%\end{array}$ & $\begin{array}{r}2009 \\
\%\end{array}$ & $\begin{array}{r}2010 \\
\%\end{array}$ & $\begin{array}{r}2011 \\
\%\end{array}$ \\
\hline HUDEBR & Debrecen/Hungary & $21.58 / 47.53$ & 90 & 92 & 84 & 92 & 92 & 100 & 98 \\
\hline HUGYOE & Gyoyer/Hungary & $17.60 / 47.67$ & 90 & 92 & 92 & 92 & 100 & 100 & 100 \\
\hline HRZAGR & Zagreb/Croatia & $16.00 / 45.80$ & 83 & 76 & 100 & 81 & 70 & 96 & 88 \\
\hline VELIKA & Velika-Gorica/Croatia & $16.38 / 45.78$ & 0 & 0 & 0 & 100 & 100 & 83 & 100 \\
\hline SAMOBOR & Samobor/Croatia & $15.71 / 45.80$ & 0 & 0 & 0 & 100 & 100 & 100 & 82 \\
\hline IVANIC & Ivanic-Grad/Croatia & $16.07 / 45.70$ & 0 & 0 & 0 & 100 & 82 & 100 & 100 \\
\hline SLAVONSKI & Slavonski/Croatia & $18.02 / 45.15$ & 0 & 0 & 0 & 100 & 100 & 100 & 100 \\
\hline BJELOVAR & Bjelovar/Croatia & $16.84 / 45.89$ & 100 & 100 & 100 & 100 & 100 & 100 & 0 \\
\hline ROUSSILLON & Lyon/France & $4.81 / 45.37$ & 77 & 75 & 83 & 71 & 82 & 71 & 89 \\
\hline
\end{tabular}

10915

Table 2. Meteorological variables used for the correlation calculations to the ragweed pollen concentrations. For the "morning" values, the average and the difference are calculated using the hourly data between 03:00 UTC and 12:00 UTC.

\begin{tabular}{lll}
\hline Variable & Symbol & Unit \\
\hline $2 \mathrm{~m}$ temperature & $T_{2 \mathrm{~m}}$ & $\mathrm{~K}^{-1}$ \\
$2 \mathrm{~m}$ specific humidity & $q_{2 \mathrm{~m}}$ & $\mathrm{~g} \mathrm{~g}^{-1}$ \\
Friction velocity & $u_{*}$ & $\mathrm{~m} \mathrm{~s}^{-1}$ \\
Convective velocity scale & $W_{*}$ & $\mathrm{~m} \mathrm{~s}^{-1}$ \\
Precipitation rate & $\mathrm{Pr}$ & $\mathrm{mm} \mathrm{h}^{-1}$ \\
Boundary layer height & $\mathrm{BLH}$ & $\mathrm{m}$ \\
Surface sensible heat flux & $Q_{0}$ & $\mathrm{~W} \mathrm{~m}^{-2}$ \\
Downward shortwave radiation flux & $\mathrm{SW}$ & $\mathrm{W} \mathrm{m}^{-2}$ \\
\hline Mean daily value & $d_{\text {mean }}$ & \\
Maximum daily value & $d_{\text {max }}$ & \\
Mean morning value & $d_{\text {morn }}$ & \\
Morning temporal gradient & $\Delta_{\text {morn }}$ & \\
\hline
\end{tabular}


Table 3. Correlation, $r$, and significance, $p_{\mathrm{sl}}$, between ragweed concentrations and meteorological variables for four stations: ROUSSILLON, HUDEBR, HRZAGR and VELIKA and the year 2010.

\begin{tabular}{|c|c|c|c|c|}
\hline Station & $d_{\text {mean }}$ & $d_{\max }$ & $d_{\text {morn }}$ & $\Delta_{\text {morn }}$ \\
\hline \multicolumn{5}{|c|}{ ROUSSILLON } \\
\hline & $r\left(p_{\mathrm{sl}}\right)$ & $r\left(p_{\mathrm{sl}}\right)$ & $r\left(p_{\mathrm{sl}}\right)$ & $r\left(p_{\mathrm{sl}}\right)$ \\
\hline$T_{2 \mathrm{~m}}$ & $0.66(0.00)$ & $0.63(0.00)$ & $0.65(0.00)$ & $0.18(0.18)$ \\
\hline$q_{2 \mathrm{~m}}$ & $0.40(0.0$ & $40(0.00)$ & $0.32(0.01)$ & $-0.11(0.41)$ \\
\hline$u_{*}$ & $0.11(0.42$ & $0.11(0.39)$ & $0.10(0.47)$ & $-0.14(0.29)$ \\
\hline$w_{*}$ & $0.17(0.2$ & $.37(0.0$ & $0.22(0.09)$ & $0.00(1.00)$ \\
\hline $\mathrm{Pr}$ & $5(0.72)$ & $0.00(0.99)$ & $-0.10(0.47)$ & $-0.08(0.54)$ \\
\hline BLH & $0.33(0.01)$ & $0.51(0.00)$ & $0.37(0.00)$ & $0.45(0.00)$ \\
\hline$Q_{0}$ & -0.0 & $1(0$. & $5(0$. & $0.18(0.19)$ \\
\hline $\mathrm{SW}_{\mathrm{d}}$ & $0.12(0.36)$ & $0.18(0.17)$ & & $0.17(0.20)$ \\
\hline \multicolumn{5}{|c|}{ HUDEBR } \\
\hline & $r\left(p_{\mathrm{sl}}\right)$ & $r\left(p_{\mathrm{sl}}\right)$ & $r\left(p_{\mathrm{sl}}\right)$ & $r\left(p_{\mathrm{sl}}\right)$ \\
\hline$T_{2 \mathrm{~m}}$ & $0.41(0.00)$ & $0.42(0.00)$ & $0.44(0.00)$ & $-0.13(0.27)$ \\
\hline$q_{2 \mathrm{~m}}$ & $0.32(0.01)$ & $0.37(0.00)$ & $0.33(0.00)$ & $0.24(0.04)$ \\
\hline$u_{*}$ & $-0.26(0.02)$ & $-0.16(0.18)$ & $-0.18(0.12)$ & $-0.06(0.59)$ \\
\hline$W_{*}^{*}$ & $0.04(0.74)$ & $0.15(0.20)$ & $0.15(0.19)$ & $0.00(1.00)$ \\
\hline $\operatorname{Pr}$ & $0.13(0.25)$ & $0.21(0.07)$ & $0.24(0.04)$ & $0.38(0.00)$ \\
\hline BLH & $-0.03(0.79)$ & $0.20(0.09)$ & $0.23(0.05)$ & $0.24(0.04)$ \\
\hline$Q_{0}$ & $-0.01(0.93)$ & $0.02(0.85)$ & $0.05(0.69)$ & $-0.20(0.09)$ \\
\hline $\mathrm{SW}_{\mathrm{d}}$ & $0.37(0.00)$ & $0.38(0.00)$ & $0.37(0.00)$ & $-0.07(0.55)$ \\
\hline
\end{tabular}

10917

Table 3. Continued.

\begin{tabular}{|c|c|c|c|c|}
\hline Station & $d_{\text {mean }}$ & $d_{\max }$ & $d_{\text {morn }}$ & $\Delta_{\text {morn }}$ \\
\hline \multicolumn{5}{|c|}{ HRZAGR } \\
\hline & $r\left(p_{\mathrm{sl}}\right)$ & $r\left(p_{\mathrm{sl}}\right)$ & $r\left(p_{\mathrm{sl}}\right)$ & $r\left(p_{\mathrm{sl}}\right)$ \\
\hline$T_{2 \mathrm{~m}}$ & $0.22(0.13)$ & $0.35(0.01)$ & $0.29(0.05)$ & $0.19(0.19)$ \\
\hline$q_{2 \mathrm{~m}}$ & $-0.08(0.58)$ & $-0.05(0.71)$ & $-0.06(0.68)$ & $-0.22(0.14)$ \\
\hline$u_{*}$ & $-0.23(0.12)$ & $-0.18(0.21)$ & $-0.10(0.50)$ & $0.01(0.95)$ \\
\hline$w_{*}$ & 0.24 (0.09) & $0.27(0.06)$ & $0.31(0.03)$ & $0.00(1.00)$ \\
\hline $\operatorname{Pr}$ & $-0.07(0.65)$ & $-0.08(0.60)$ & $-0.09(0.55)$ & $-0.09(0.53)$ \\
\hline BLH & $-0.09(0.53)$ & $0.11(0.45)$ & $0.11(0.44)$ & $0.07(0.64)$ \\
\hline$Q_{0}$ & $0.44(0.00)$ & $0.42(0.0$ & $0.40(0 . C$ & $0.20(0.16)$ \\
\hline $\mathrm{SW}_{\mathrm{d}}$ & $0.28(0.05)$ & $0.30(0.04)$ & $0.29(0.05)$ & $0.11(0.46)$ \\
\hline \multicolumn{5}{|c|}{ VELIKA } \\
\hline & $r\left(p_{\mathrm{sl}}\right)$ & $r\left(p_{\mathrm{sl}}\right)$ & $r\left(p_{\mathrm{sl}}\right)$ & $r\left(p_{\mathrm{sl}}\right)$ \\
\hline$T_{2 \mathrm{~m}}$ & $0.35(0.01)$ & $0.32(0.02)$ & $0.33(0.02)$ & $-0.02(0.92)$ \\
\hline$q_{2 \mathrm{~m}}$ & $0.32(0.02)$ & $0.35(0.01)$ & $0.23(0.10)$ & $-0.16(0.28)$ \\
\hline$u_{*}$ & $-0.06(0.68)$ & $-0.04(0.78)$ & $0.06(0.68)$ & $-0.12(0.39)$ \\
\hline$w_{*}$ & $0.34(0.01)$ & $0.38(0.01)$ & $0.43(0.00)$ & $0.00(1.00)$ \\
\hline $\operatorname{Pr}$ & $-0.06(0.70)$ & $0.04(0.78)$ & $-0.03(0.81)$ & $0.40(0.00)$ \\
\hline BLH & $0.15(0.31)$ & $0.27(0.06)$ & $0.35(0.01)$ & $0.18(0.22)$ \\
\hline$Q_{0}$ & $0.44(0.00)$ & $0.43(0.00)$ & $0.44(0.00)$ & $0.23(0.10)$ \\
\hline $\mathrm{sW}_{\mathrm{d}}$ & $0.34(0.02)$ & $0.34(0.02)$ & $0.36(0.01)$ & $0.11(0.45)$ \\
\hline
\end{tabular}


Table 4. Julian day for the start of the pollen season (day when $5 \%$ of the annual pollen sum is reached) and number of days of the season (between the $5 \%$ and $95 \%$ of the annual pollen sum). The empty lines are for station and year with no data, as explained in Table 1.

\begin{tabular}{lrrrrrrr}
\hline Station & 2005 & 2006 & 2007 & 2008 & 2009 & 2010 & 2011 \\
\hline BJELOVAR & $229+29$ & $230+29$ & $226+33$ & $225+29$ & $223+33$ & $227+30$ & - \\
HRZAGR & $230+26$ & $229+29$ & $222+37$ & $232+21$ & $224+27$ & $224+39$ & $229+27$ \\
HUDEBR & $219+43$ & $228+45$ & $218+49$ & $223+34$ & $226+31$ & $227+30$ & $224+42$ \\
HUGYOE & $223+36$ & $231+45$ & $226+41$ & $224+33$ & $223+39$ & $227+41$ & $230+30$ \\
IVANIC & - & - & - & $224+30$ & $222+31$ & $231+25$ & $230+38$ \\
ROUSSILLON & $227+33$ & $230+25$ & $224+35$ & $229+26$ & $224+34$ & $230+31$ & $222+35$ \\
SAMOBOR & - & - & - & $228+30$ & $225+29$ & $232+41$ & $230+39$ \\
SLAVONSKI & - & - & - & $223+33$ & $224+39$ & $230+29$ & $228+32$ \\
VELIKA & - & - & - & $224+30$ & $222+32$ & $230+26$ & $230+27$ \\
\hline
\end{tabular}

10919

Table 5. Correlations between observations and the three formulations of the emission release module. E2011 and S2013 stand for Efstathiou et al. (2011) and Sofiev et al. (2013), respectively. Results are presented for stations BJELOVAR, HRZAGR, HUDEBR and HUGYOE. For each station and each year, the best correlation is highlighted in bold.

\begin{tabular}{|c|c|c|c|}
\hline Year & E2011 & S2013 & This study \\
\hline \multicolumn{4}{|c|}{ BJELOVAR } \\
\hline & $r\left(p_{\mathrm{sl}}\right)$ & $r\left(p_{\mathrm{sl}}\right)$ & $r\left(p_{\mathrm{sl}}\right)$ \\
\hline 2005 & $0.64(0.00)$ & $0.77(0.00)$ & $0.77(0.00)$ \\
\hline 2006 & 0.75 & 0.79 & $0.77(0.00)$ \\
\hline 2007 & 0.54 & 0.63 & $0.78(0.00)$ \\
\hline 2008 & $0.76(0.00)$ & $0.78(0.00)$ & $0.82(0.00)$ \\
\hline 2009 & 0.39( & 0.57( & $0.75(0.00)$ \\
\hline 2010 & $0.32(0.02)$ & $0.50(0.00)$ & $0.53(0.00)$ \\
\hline \multicolumn{4}{|c|}{ HRZAGR } \\
\hline & $r\left(p_{\mathrm{sl}}\right)$ & $r\left(p_{\mathrm{sl}}\right)$ & $r\left(p_{\mathrm{sl}}\right)$ \\
\hline 2005 & $0.79(0.00)$ & $0.77(0.00)$ & $0.72(0.00)$ \\
\hline 2006 & $0.50(0.00)$ & $0.62(0.00)$ & $0.63(0.00)$ \\
\hline 2007 & $0.62(0.00)$ & $0.66(0.00)$ & $0.56(0.00)$ \\
\hline 2008 & $0.83(0.00)$ & $0.84(0.00)$ & $0.79(0.00)$ \\
\hline 2009 & $0.38(0.01)$ & $0.43(0.00)$ & $0.47(0.00)$ \\
\hline 2010 & $0.44(0.00)$ & $0.59(0.00)$ & $0.66(0.00)$ \\
\hline 2011 & $0.42(0.00)$ & $0.50(0.00)$ & $0.41(0.00)$ \\
\hline
\end{tabular}


Table 5. Continued.

\begin{tabular}{|c|c|c|c|}
\hline Year & E2011 & S2013 & This study \\
\hline \multicolumn{4}{|c|}{ HUDEBR } \\
\hline & $r\left(p_{\mathrm{sl}}\right)$ & $r\left(p_{\mathrm{sl}}\right)$ & $r\left(p_{\mathrm{sl}}\right)$ \\
\hline 2005 & $0.12(0.35)$ & $0.13(0.32)$ & $0.65(0.00)$ \\
\hline 2006 & $0.22(0.07)$ & $0.11(0.37)$ & $0.57(0.00)$ \\
\hline 2007 & $0.02(0.86)$ & $0.06(0.64)$ & $0.52(0.00)$ \\
\hline 2008 & $0.23(0.09)$ & $0.29(0.02)$ & $0.61(0.00)$ \\
\hline 2009 & $0.42(0.00)$ & $0.45(0.00)$ & $0.67(0.00)$ \\
\hline 2010 & $0.35(0.00)$ & $0.31(0.01)$ & $0.46(0.00)$ \\
\hline 2011 & $0.15(0.20)$ & $0.20(0.09)$ & $0.41(0.00)$ \\
\hline \multicolumn{4}{|c|}{ HUGYOE } \\
\hline & $r\left(p_{\mathrm{sl}}\right)$ & $r\left(p_{\mathrm{sl}}\right)$ & $r\left(p_{\mathrm{sl}}\right)$ \\
\hline 2005 & $0.64(0.00)$ & $0.70(0.00)$ & $0.72(0.00)$ \\
\hline 2006 & $0.55(0.00)$ & $0.58(0.00)$ & $0.53(0.00)$ \\
\hline 2007 & $0.36(0.00)$ & $0.41(0.00)$ & $0.47(0.00)$ \\
\hline 2008 & $0.76(0.00)$ & $0.71(0.00)$ & $0.67(0.00)$ \\
\hline 2009 & $0.25(0.04)$ & $0.43(0.00)$ & $0.58(0.00)$ \\
\hline 2010 & $0.16(0.18)$ & $0.17(0.16)$ & $0.20(0.10)$ \\
\hline 2011 & $0.04(0.74)$ & $-0.01(0.95)$ & $0.21(0.10)$ \\
\hline
\end{tabular}

10921

Table 6. Correlations between observations and the three formulations of the emission release module. E2011 and S2013 stand for Efstathiou et al. (2011) and Sofiev et al. (2013), respectively. Results are presented for stations ROUSSILLON, SAMOBOR, SLAVONSKI and VELIKA. For each station and each year, the best correlation is highlighted in bold.

\begin{tabular}{|c|c|c|c|}
\hline Year & E2011 & S2013 & This study \\
\hline \multicolumn{4}{|c|}{ ROUSSILLON } \\
\hline & $r\left(p_{\mathrm{sl}}\right)$ & $r\left(p_{\mathrm{sl}}\right)$ & $r\left(p_{\mathrm{sl}}\right)$ \\
\hline 2005 & $0.63(0.00)$ & $0.67(0.00)$ & $0.73(0.00)$ \\
\hline 2006 & $0.72(0.00)$ & $0.77(0.00)$ & $0.79(0.00)$ \\
\hline 2007 & $0.46(0.00)$ & $0.59(0.00)$ & $0.70(0.00)$ \\
\hline 2008 & $0.78(0.00)$ & $0.79(0.00)$ & $0.79(0.00)$ \\
\hline 2009 & $0.54(0.00)$ & $0.62(0.00)$ & $0.74(0.00)$ \\
\hline 2010 & $0.55(0.00)$ & $0.60(0.00)$ & $0.67(0.00)$ \\
\hline 2011 & $0.63(0.00)$ & $0.64(0.00)$ & $0.68(0.00)$ \\
\hline \multicolumn{4}{|c|}{ SAMOBOR } \\
\hline & $r\left(p_{\mathrm{sl}}\right)$ & $r\left(p_{\mathrm{sl}}\right)$ & $r\left(p_{\mathrm{sl}}\right)$ \\
\hline 2008 & $0.51(0.00)$ & $0.63(0.00)$ & $0.69(0.00)$ \\
\hline 2009 & $0.60(0.00)$ & $0.68(0.00)$ & $0.82(0.00)$ \\
\hline 2010 & $0.41(0.00)$ & $0.53(0.00)$ & $0.52(0.00)$ \\
\hline 2011 & $0.37(0.01)$ & $0.43(0.00)$ & $0.48(0.00)$ \\
\hline \multicolumn{4}{|c|}{ SLAVONSKI } \\
\hline & $r\left(p_{\mathrm{sl}}\right)$ & $r\left(p_{\mathrm{sl}}\right)$ & $r\left(p_{\mathrm{sl}}\right)$ \\
\hline 2008 & $0.74(0.00)$ & $0.73(0.00)$ & $0.79(0.00)$ \\
\hline 2009 & $0.58(0.00)$ & $0.58(0.00)$ & $0.60(0.00)$ \\
\hline 2010 & $0.78(0.00)$ & $0.78(0.00)$ & $0.67(0.00)$ \\
\hline 2011 & $0.60(0.00)$ & $0.55(0.00)$ & $0.57(0.00)$ \\
\hline \multicolumn{4}{|c|}{ VELIKA } \\
\hline & $r\left(p_{\mathrm{sl}}\right)$ & $r\left(p_{\mathrm{sl}}\right)$ & $r\left(p_{\mathrm{sl}}\right)$ \\
\hline 2008 & $0.79(0.00)$ & $0.85(0.00)$ & $0.90(0.00)$ \\
\hline 2009 & $0.50(0.00)$ & $0.63(0.00)$ & $0.81(0.00)$ \\
\hline 2010 & $0.45(0.00)$ & $0.50(0.00)$ & $0.39(0.00)$ \\
\hline 2011 & $0.34(0.02)$ & $0.34(0.01)$ & $0.44(0.00)$ \\
\hline
\end{tabular}




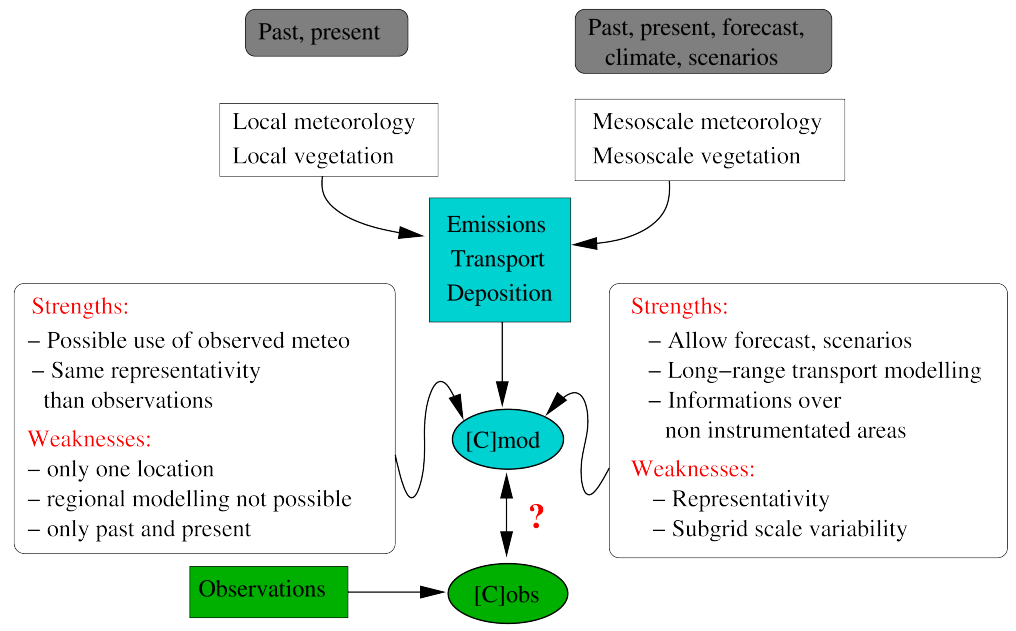

Fig. 1. Flowchart of pollen modelling at local or regional scale with strengths and weaknesses of each approach.

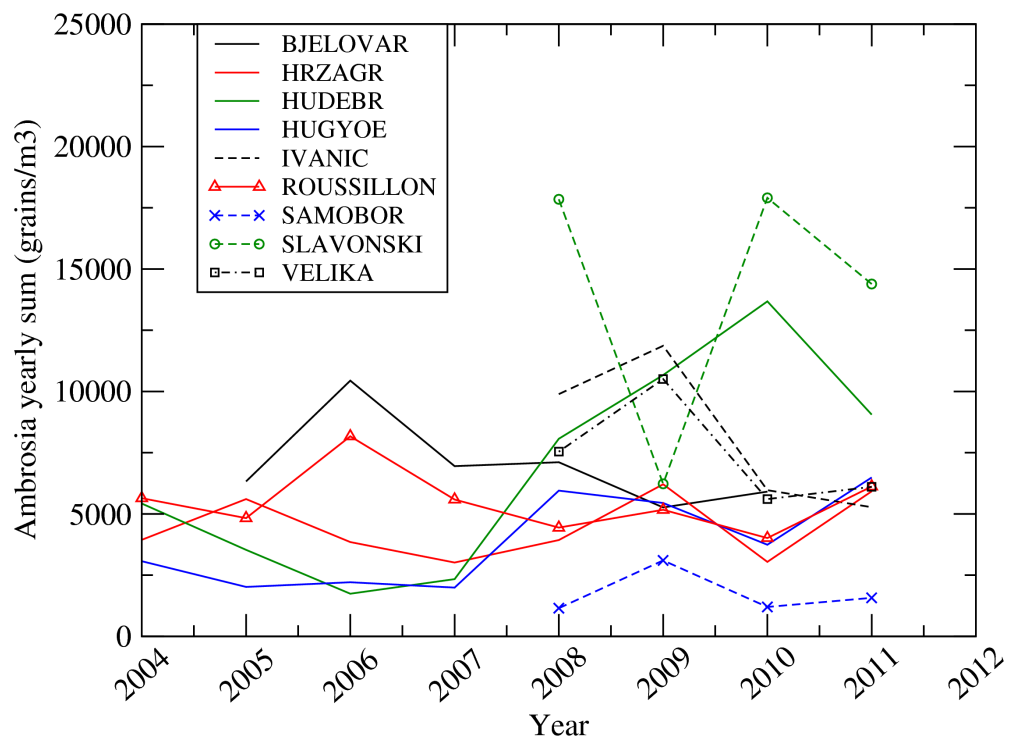

Fig. 2. Annual sum of measured ambrosia concentrations (grains $\mathrm{m}^{-3}$ ) for selected sites and from 2004 to 2011. 

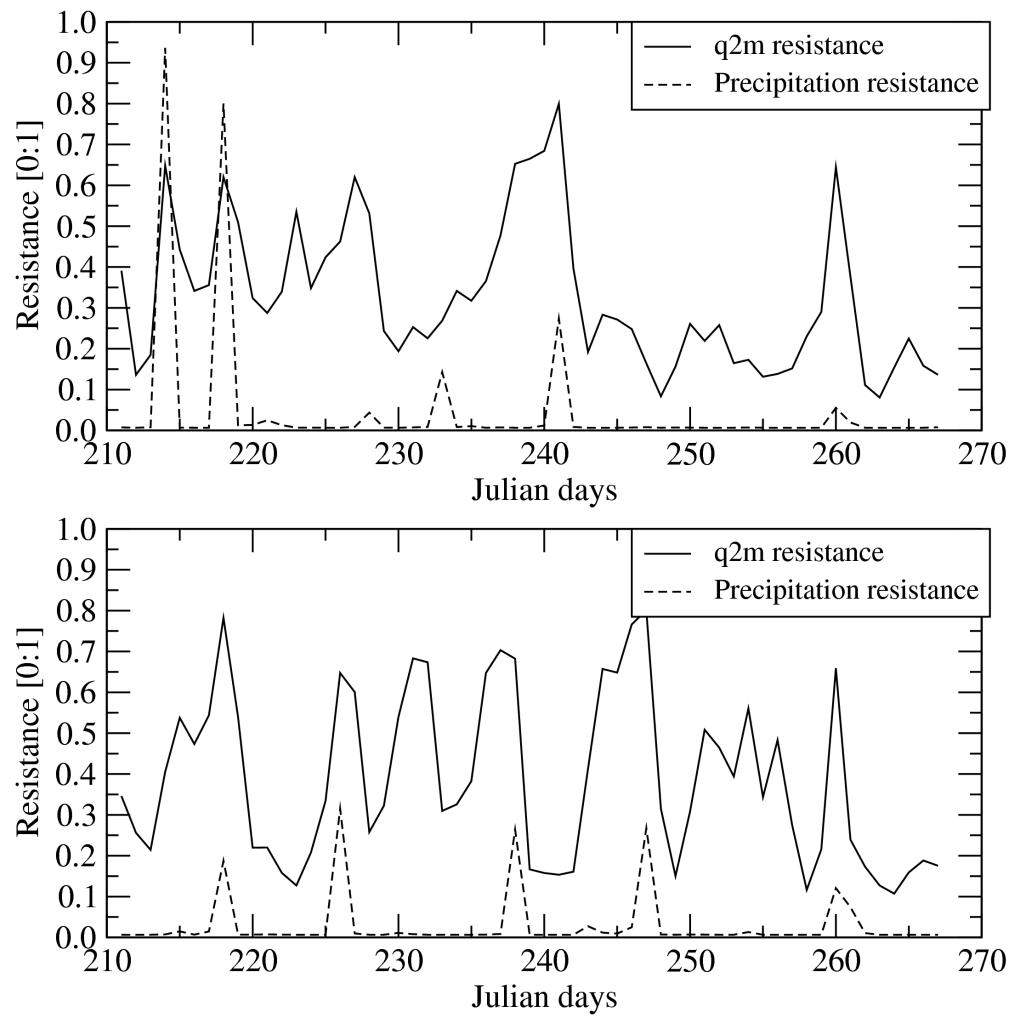

Fig. 3. Values of resistances for the ROUSSILLON site and the years 2007 (top) and 2011 (bottom).

10925
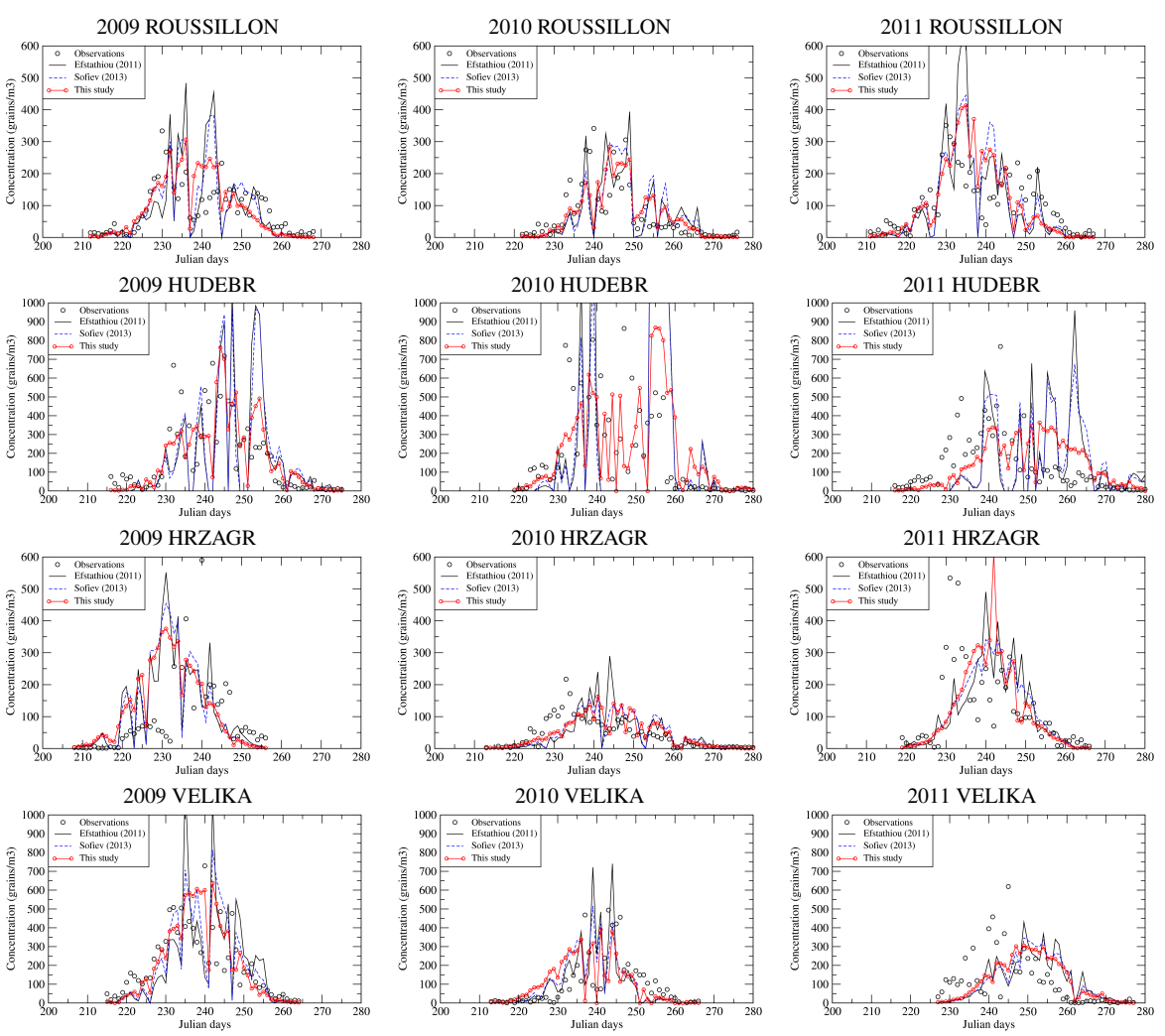

Fig. 4. Observed surface concentrations and modelled emissions for the ROUSSILLON, HUDEBR, HRZAGR and VELIKA sites and the years of 2009, 2010 and 2011. 

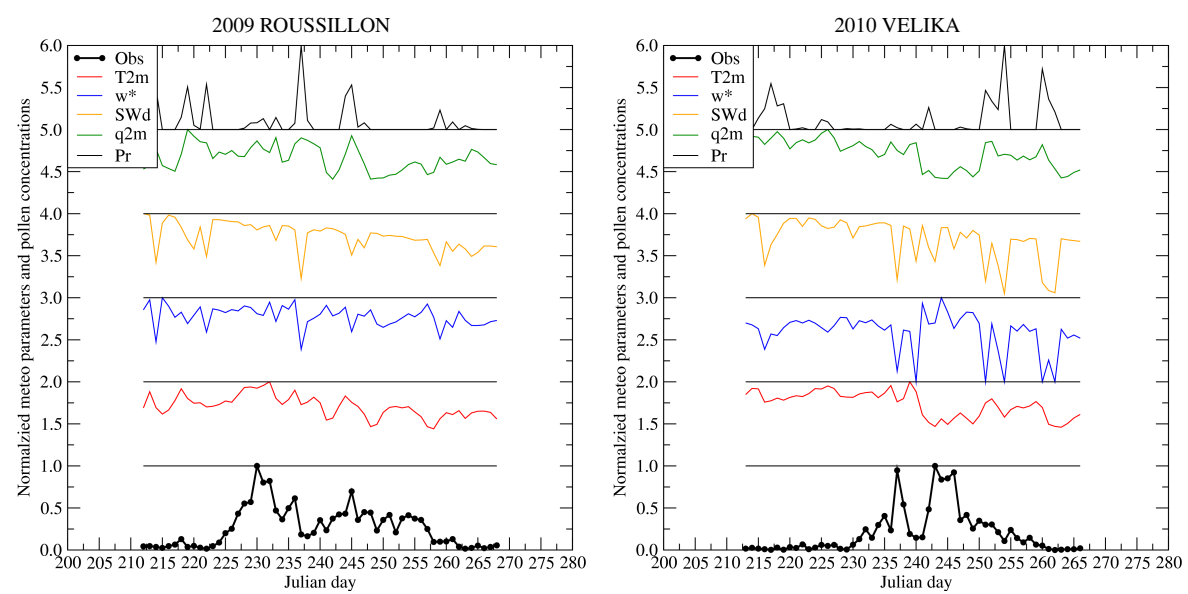

Fig. 5. Observed surface concentrations and corresponding modelled meteorological variables for the ROUSSILLON (2009) and VELIKA (2010) sites. 